\title{
Influência dos enunciados na resolução de problemas de programação introdutória
}

\author{
Influence of problems statement style on Introductory Programming Learning
}

\section{André Luís Alice Raabe}

Programa de Mestrado em Computação Aplicada

Programa de Pós-Graduação em Educação

Laboratório de Inovação Tecnológica na Educação, LITE

Universidade do Vale do Itajaí - UNIVALI

raabe@univali.br

\section{Adriana Salvador Zanini}

Programa de pós-graduação em Ciência da Computação Universidade do Vale do Itajaí - UNIVALI

adriana.zanini@unisul.br

\author{
André Luiz Maciel Santana \\ Programa de Mestrado em Computação Aplicada \\ Laboratório de Inovação Tecnológica na Educação, LITE \\ Universidade do Vale do Itajaí - UNIVALI \\ andrelms@univali.br
}

\author{
Marli Fátima Vick Vieira \\ Programa de Pós-Graduação em Educação \\ Universidade do Vale do Itajaí - UNIVALI \\ marli@ifc-araquari.edu.br
}

Resumo O método de ensino mais utilizado, em disciplinas de programação introdutória, é a proposição de problemas em que apresenta-se um enunciado com um problema descrito e os estudantes elaboram um algoritmo para solucioná-lo. Muitas são as dificuldades apresentadas pelos estudantes, principalmente relacionadas à compreensão e interpretação do enunciado. Esta pesquisa analisou os enunciados apresentados nos livros didáticos mais frequentemente adotados em universidades brasileiras, e constatou que geralmente são objetivos, sem indícios do processo de resolução, sem exemplificação e com um contexto predominantemente matemático. Nesse cenário formulou-se a questão de pesquisa: a estrutura elou o contexto de um enunciado podem influenciar o desempenho dos alunos, de programação introdutória na resolução de problemas? A estrutura está relacionada aos elementos que constam no enunciado para auxiliar o estudante a compreendê-lo tais como exemplos, casos de testes ou indícios da solução. O contexto se refere ao tema/enredo da questão. Partiu-se da crença de que em contextos que o estudante possui maior familiaridade, como jogos, compreenderá melhor os problemas e poderá ter melhor desempenho. Para responder esta questão realizou-se uma pesquisa experimental para avaliar a influência dos enunciados no desempenho dos estudantes ao resolverem problemas de programação introdutória. Foram propostos problemas usando dois contextos: matemático e jogos e dois tipos de estrutura: estruturado e não estruturado formando assim quatro grupos de tratamento. No experimento participaram 246 estudantes de oito turmas de seis instituições de ensino superior de três diferentes estados de diferentes regiões geográficas do Brasil. Os resultados apontaram que os estudantes tiveram melhor desempenho quando os enunciados são estruturados e que este é acentuado quando o contexto é matemático. Não foi encontrada nenhuma evidência de que a utilização do contexto de jogos nos enunciados favoreceu o desempenho. O pior desempenho ocorreu o grupo de questões do contexto matemático não estruturado, justamente o modelo de enunciado mais frequentemente encontrado nos livros didáticos, o que leva a conclusão de que é necessário repensar a forma de apresentar os problemas aos estudantes de programação introdutória.

Palavras-Chave: Aprendizagem de Programação; Educação em Computação; Resolução de Problemas; Teoria da Relevância; Teoria da Aprendizagem Significativa.

\footnotetext{
Abstract Most used teaching method in Introductory Programing is the proposition of problems, in which is presented the enunciation with a described problem and, from it is elaborated an algorithm to solve it. There are several difficulties presented, mainly related to the comprehension and interpretation of the enunciation. Analyzing the enunciations presented in textbooks used in Brazil, it
} 
was observed that, generally, they are objectives, without evidences of the process of solving and without exemplification, in a purely Mathematics context. In this scenery, it was formulated the research question: the structure and/or context of an enunciation have influence upon the performance of Introductory Programming students in the problem solving? For answer it, research on relevance theory and learning theory and a significant an experiment was carried out in order to test the enunciations, considering context and structure; in the context we used the math, the traditional and the games, the motivator; and for structure was used the non-structured shape, traditional, and structured with complete data. In this experiment, eight classes of students have participated and they are from six Brazilian Higher Education Institution. The students were distributed in four groups, considering the profile and each group solve a type of evaluation and answer a questionnaire. Three analyses were carried out. On the first one, a test of hypothesis was performed, relating the context and the structure with the performance of students, using the logistic regression technique. It was observed statistical difference related to the structure, mainly when the context is math. It was also presented differences related to the student base-performance. On the second analysis was verified the solutions presented and on the third the answers of final questionnaire were analyzed. The worst result was presented by the group which performed the evaluation in non-structured math context, which is the model traditionally used. The best result was on structured math, what lead us to conclude that invest efforts worth in the elaboration of enunciation.

Keywords: Programming Learning; Computer Science Education; Problem solving; Relevance Theory; Meaningful Learning Theory. 


\section{Introdução}

Os cursos da área de computação e informática tem como base a disciplina de Programação Introdutória ${ }^{1}$, que, objetiva desenvolver a capacidade de transformar problemas gerais em soluções algorítmicas ${ }^{2}$. Essa disciplina é oferecida nas fases iniciais e recebe diferentes denominações como Algoritmos, Lógica de Programação entre outras.

O processo de aprendizagem de programação introdutória é difícil para a maioria dos alunos, mesmo quando envolvem apenas os conceitos básicos. Esta dificuldade é comum em diversas instituições de ensino, com índice de evasão e reprovação de até $60 \%$ [1,2].

Uma das principais razões pelo índice de reprovação e, até mesmo, desistência do curso é citada por Santos e Costa [3] como sendo a falta de compreensão dos problemas e o raciocínio lógico. Os autores afirmam que cabe ao professor fazer o aluno compreender a abstração do problema e sua resolução e, para isso, deve ser criativo e propor problemas contextualizados em situações do cotidiano do aluno. Nesse sentido, realizaram-se muitos estudos focados na utilização e criação de softwares como: ambientes de programação simples e colaborativos, sistemas tutores inteligentes e outros.

Para uma aprendizagem mais efetiva, essa deve ser significativa e, para isso, duas condições tornam-se necessárias: o material a ser aprendido deve ser potencialmente significativo para o aluno, relacionável a sua estrutura de conhecimento de forma não arbitrária e não literal (substantiva); e o aluno deve estar motivado a aprender, queira relacionar o novo material de maneira substantiva e não arbitrária a sua estrutura cognitiva [4].

Nessa visão, o professor tem de criar estratégias de ensino e aprendizagem que promovam o relacionamento entre o que será ensinado ao que o aluno já sabe, bem como, criar estratégias para que o aluno sinta-se motivado em querer aprender, assim, deve aproximar-se da vivência do aluno que, conforme Mattar [5] está imerso em tecnologias, como: televisões, videogames, computadores e dispositivos móveis.

Becker e Parker [6] fizeram um estudo com os alunos ingressantes no curso de Ciência da Computação, na universidade onde atuam, verificaram que de $65 \%$ a $75 \%$ dos

\footnotetext{
${ }^{1}$ Programação Introdutória e Algoritmo são tratados como sinônimos. Referem-se à disciplina e conteúdos relacionados à lógica de programação, em que, o objetivo é a construção de passos lógicos e finitos para resolver um determinado problema.

Limita-se ao processo inicial de construção de algoritmos. Não é foco desse estudo a otimização ou eficiência de processos ou códigos, nem a codificação em uma linguagem de programação específica.
}

alunos ingressantes foram em busca do curso porque jogam videogame. Os autores afirmam que os problemas eram melhores compreendidos quando relacionados aos jogos. Esse estudo aponta os jogos como um contexto interessante para ser trabalhado em sala de aula, além de promover motivação, é um elemento conhecido dos alunos, podendo facilitar a conexão entre o que se deseja ensinar e às estruturas cognitivas já existentes no aluno.

Considerando os alunos de hoje como nativos digitais,por nascerem imersos em um mundo de tecnologias, acredita-se que o contexto de jogos é uma situação do cotidiano deles [8]. Segundo Cliburn [9] e Bayllis [10] há um crescente interesse dos professores pela utilização de jogos na Educação, visto que fazem parte da realidade cultural dos alunos.

Feldgen e Clúa [11] indicam jogos como uma ótima forma de iniciar o desenvolvimento das habilidades de resolução de problemas. Conforme Cliburn [9] os alunos preferem exercícios relacionados a jogos ao invés dos tradicionais.

Uma forma "simplificada" de utilizar jogos no ensino de algoritmos seria contextualizando os problemas, a serem resolvidos, nesse contexto. $\mathrm{O}$ aluno não teria como objetivo a construção ou a utilização de um jogo, mas, resolver um problema dentro desse universo.

Jesus e Raabe [12] pesquisaram nesse sentido, verificando se enunciados mais contextualizados ${ }^{3}$ influenciavam no desempenho do aluno. Neste contexto, os experimentos foram realizados com três turmas de alunos ingressantes em Ciência da Computação, totalizando 40 estudantes. Os experimentos ocorreram ao longo das 18 semanas de aula (um semestre letivo) e abordaram conceitos de loop, vetores e desvios condicionais, sendo consideradas uma turma como grupo de controle e duas como grupo experimental.

Usou-se três níveis de contextualização (alto, médio, baixo), no nível mais alto os problemas foram resolvidos dentro de um jogo, cujo enredo serviu como contexto para os problemas algorítmicos. No nível médio, os alunos utilizaram outro software para resolver o problema, o qual foi apresentado impresso, contendo descrições textuais e imagens dos cenários e situações do jogo. A grande diferença entre os dois níveis era que, no primeiro, os alunos jogaram o jogo e, no segundo, apenas o imaginaram. No nível mais baixo de contextualização os enunciados dos problemas foram apresentados de forma mais abstrata, sem nenhuma

\footnotetext{
${ }^{2}$ Uma sequência de ações claras e precisas (passos lógicos e finitos) que devem ser seguidas para resolver um determinado problema [7].

${ }^{3}$ Contextualização foi tratada no trabalho de Jesus e Raabe [12] como a evidencia da utilidade da solução de um problema descrito no enunciado. Quanto mais evidente, mais contextualizado.
} 
referência ao jogo, como é comum nos livros didáticos da área. Com o experimento realizado não foi possível, devido à mortalidade seletiva ${ }^{1,}$ obter evidências significativas de que o uso do contexto de jogos melhora a aprendizagem, mas, observaram indícios de melhora no progresso dos alunos considerando os níveis da Taxonomia de Bloom ${ }^{2}$ no domínio cognitivo. Nestas atividades foram utilizados o Alice ${ }^{3}$ e o Scratch ${ }^{4}$.

Muitas vezes busca-se por novas estratégias de ensino e aprendizagem de programação introdutória como a criação e utilização de novas ferramentas, deixando de lado um elemento fundamental do processo de resolução de problemas, o enunciado. Visto que o método de ensino mais utilizado em disciplinas de programação introdutória é a proposição de problemas [13], em que os alunos recebem um enunciado, com um problema descrito, e a partir desse, elaboram um algoritmo para solucioná-lo.

Ao vivenciar este processo, muitos alunos apresentam dificuldades com a compreensão e interpretação do enunciado, não abstraem corretamente as informações relacionadas ao que deve ser feito, bem como, ao como resolver o problema proposto. Isso implica em uma solução incorreta ou, até mesmo, a não resolução do problema [12].

Zanini e Raabe [14] constataram que os enunciados, apresentados nos livros didáticos adotados no Brasil, geralmente, são objetivos, não apresentam indícios do processo de resolução, não possuem exemplos e o contexto é puramente matemático, tornando-os mais abstratos. Conforme Jesus e Raabe [12] os enunciados, comumente, resumem-se a "calcule isto" e "resolva aquilo" e o resultado do cálculo, da resolução, não é utilizado para algo que faça sentido dentro de um contexto maior.

Assim, acredita-se que uma das dificuldades encontradas, na resolução de problemas, está relacionada à estrutura e/ou contexto do enunciado, em que, os dados contidos ou omitidos e a falta de relacionamento com as experiências e vivência do aluno, torna-o abstrato e irrelevante. Observa-se a existência de relação inversamente proporcional entre a contextualização ${ }^{5}$ de um enunciado e o seu nível de abstração. Quanto menos contextualizado o enunciado, mais abstrato ele se torna e vice-versa [12].

Considerando os enunciados dos problemas algorítmicos como sendo um fator fundamental para o processo de resolução de problemas, verificou-se nesta pesquisa se a estrutura e/ou contexto de um enunciado influenciam o desempenho dos alunos de programação introdutória na re-

\footnotetext{
${ }^{1}$ Mortalidade seletiva ocorre quando os participantes que iniciaram o experimento desistem antes de conclui-lo.

${ }^{2}$ A taxionomia de Bloom é uma estrutura com três domínios: o cognitivo, o afetivo e o psicomotor. O domínio cognitivo é subdividido em seis categorias (níveis): lembrar, entender, aplicar, analisar, avaliar e criar.
}

solução de problemas. Os fundamentos para apoiar a crenças de que o contexto é importante foram construídos com base na Teoria da Relevância e na Teoria da Aprendizagem Significativa apresentadas na seção 2 .

A pesquisa utilizou uma abordagem quase-experimental conduzindo um experimento com uma amostra de estudantes obtida por conveniência. A construção e validação do instrumento de avaliação bem como demais procedimentos metodológicos adotados são explorados em detalhes na seção 3 deste artigo. As conclusões e discussões são apresentadas na seção 4 e apontam para a necessidade de maior atenção a forma como os enunciados são elaborados.

\section{Referencial Teórico}

\subsection{Jogos na Educação}

Conforme apresentado por Papastergiou [15] estudantes sentem-se motivados quando submetidos a tarefas que envolvem o uso de jogos, uma vez que o ensino formal tende a ser entediante e pouco desafiador. $\mathrm{O}$ uso de jogos permite um feedback imediato quanto aos erros e acertos, possibilitando aos aprendizes validar hipóteses e aprender com suas próprias ações.

Mitchell e Savil-smith [16] apontam que o uso de jogos permite tanto os garotos quanto as garotas sejam atraídos por jogos. Os principais indícios de motivação podem ser identificados através de quatro aspectos: (i) persistência para permanecer jogando; (ii) autonomia para vencer os desafios; (iii) desenvolver estratégias para superar os desafios e (iv) paciência em aprender como as coisas funcionam. Os jogos viabilizam um maior interesse por parte dos jovens por conta das motivações citadas anteriormente.

Ao descreverem o uso de jogos como estratégia pedagógica, Becker e Parker [6], definem que o uso de elementos gráficos e efeitos por uma representação digital tornam possível mapear os algoritmos utilizados para resolver as soluções de forma mais natural. A possibilidade de visualizar os resultados em tempo real permite o que os autores definem como atitude de jogador: tentar e ver acontecer.

Feldegen e Clúa [11] definem três tipos de motivação: (i) a extrínseca que consiste em desejar completar uma tarefa para alcançar alguma recompensa; (ii) intrínseca que trata de um interesse particular do indivíduo e (iii) por conquistas, geralmente ocorre em pares e trata de estratégias por competição. O uso de jogos permite trabalhar todas os

Quanto maior o nível da taxionomia, maior a complexidade envolvida [12]

${ }^{3}$ http://www.alice.org

${ }^{4} \mathrm{http}: / /$ scratch.mit.edu/

${ }^{5}$ Contextualização está sendo usada como um conjunto de elementos que compõe o enunciado, ou seja, a estrutura e o contexto. 
tipos de motivação citadas anteriormente, também influencia como estratégia para conduzir exercícios de fixação em tarefas para casa.

Segundo Cliburn [9] utilizar uma estratégia com jogos, ou propor desafios em que utilizem este tipo de notação torna possível compreender assuntos ou temáticas que apresentem algum grau de dificuldade, pois a motivação proporciona ao estudante desafiado persistência ao resolver problemas. De modo geral, o autor também afirma que garotas tem menor interesse que garotos no uso de jogos competitivos.

Borges et al [17] define gamificação como aplicação dos conceitos que originalmente pertencem a jogos, em ambientes ou atividades diferentes deste meio. Os conceitos geralmente mapeados consistem em uma boa estética, mecânica para as atividades executadas e dinâmica durante os desafios.

\subsection{Enunciado}

Segundo Wilson [18], enunciado é um objeto com propriedades linguísticas, descrita pela gramática, e não linguísticas, como particularidades do falante, audiência, lugar e tempo. Ao analisar um enunciado, observa-se o significado do falante, que vai além do significado da sentença enunciada, ou seja, o que o falante pretende comunicar, de forma explícita ou implícita, em determinada ocasião.

O falante pode ter muitas intenções ao produzir um enunciado e nem todas tem a ver com comunicar um significado do falante. Um exemplo seria os enunciados de problemas algoritmos contextualizados, em que a intenção de sua elaboração não é, apenas, apresentar uma informação do contexto, mas, sim, a aplicação de determinados conceitos algorítmicos.

Conforme Wilson[18], o falante deve formular o enunciado de modo a torná-lo fácil para o ouvinte recuperar a interpretação pretendida.

O propósito da Pragmática é estudar a relação entre linguagem e contexto ao interpretar um enunciado, isto é, verificar como os significados dos falantes são compreendidos ou mal compreendidos pela audiência.

\subsection{Contexto}

Em Wilson [18], contexto pode ser definido como o ambiente físico ou situação em que o enunciado acontece ou o texto ou discurso precedente (às vezes conseguinte). Para o autor, contexto é um construto psicológico e, em uma abordagem cognitiva da Pragmática, o que importa não são os fatos textuais ou físicos, mas as representações mentais que o ouvinte constrói e usa na identificação do significado do falante.

No processo de interpretação de enunciados, o ouvinte usa elementos extras, além do ambiente físico e do discurso anterior, como conhecimento cultural, científico e senso comum, que estão representados em sua memória. Nesse processo, ele constrói algumas suposições contextuais sobre o que o falante pretendia informar. Assim, para reconhecer a interpretação pretendida de um enunciado, deve-se fazer uma escolha apropriada do contexto.

Outro fator importante, que influencia na interpretação, é a relevância da informação, pois esta pode ser relevante em um contexto, porém não em outro. Relevância é uma propriedade potencial das entradas para os processos cognitivos, sejam estímulos externos (visões, sons, enunciados, ações) ou representações internas (pensamentos, memórias, conclusões, inferências) [19].

\subsection{Teoria da Relevância}

A cognição humana é orientada pela relevância e a nova informação é relevante em um contexto quando interage com o contexto e gera um efeito cognitivo.

Um efeito cognitivo, também conhecido como efeitos contextuais, é o processamento de uma entrada em um contexto. Quanto maior o efeito cognitivo maior a relevância.

A Teoria da Relevância é uma teoria Pragmática, a qual trata a interpretação do enunciado como uma questão psicológica, em que é afetada tanto por fatores cognitivos como por fatores sociais e linguísticos, incluindo o esforço de processamento [19]. O esforço de processamento é o esforço mental necessário para perceber ou recuperar uma informação nova, acessar um contexto de informação na memória e computar os efeitos cognitivos. Por exemplo, uma situação em que a informação seja enunciada de quatro formas:

1. em uma forma claramente impressa;

2. uma fotocópia apagada;

3. rabisco manuscrito ilegível;

4. em uma língua que não tem domínio.

Os quatro enunciados estimam os mesmos efeitos cognitivos, todavia requerem esforços de processamento diferentes e, isso, pode afetar sua intuição de relevância e alterar a sua vontade de processar a informação desse enunciado.

Alguns fatores que afetam o processamento requerido para a compressão do enunciado são [19]:

1. uso recente;

2. frequência de uso;

3. complexidade linguística;

4. complexidade lógica.

A avaliação da relevância se dá pela relação de custo e benefício dos efeitos cognitivos e dos esforços de processamento necessário para recuperar tais efeitos. Assim, quanto maior os efeitos cognitivos e menores os esforços 
de processamentos, maior a relevância.

Sperber e Wilson [19] afirmam que a cognição humana tende a ser dirigida para a maximização da relevância. Quanto mais relevante for o enunciado, mais provavelmente prenderá a atenção do ouvinte e apontará para o significado pretendido. Em busca da relevância ótima, os autores apontam duas condições para o enunciado:

1. deve ser ao menos relevante o suficiente para merecer processamento;

2. deve ser compatível com as habilidades e as preferências do falante.

A primeira condição, também, depende muito do interesse e motivações do ouvinte, pois o que é relevante para um ouvinte pode não ser para o outro, bem como para o mesmo ouvinte em outra ocasião.

A segunda condição está relacionada às habilidades $\mathrm{e}$ pretensões do falante. Uma das dificuldades se dá por não se conhecer o que está na mente dos ouvintes e, assim, fazer predições erradas sobre o que é visto como relevante para eles.

Deste modo, o falante que objetiva a relevância ótima deve tentar alcançar suficientes efeitos cognitivos para valer o processamento e evitar causar no ouvinte algum desperdício de esforço para alcançar esses efeitos.

\subsection{Aprendizagem Significativa}

Na concepção de Ausubel [20], a aprendizagem se dá de forma mecânica ou significativa e pode ocorrer através da descoberta ou da recepção.

$\mathrm{Na}$ aprendizagem mecânica, o novo conteúdo tem pouca ou nenhuma associação com conceitos relevantes existentes na estrutura cognitiva do aprendiz e é armazenado de forma arbitrária, aleatória $[4,21]$. $\mathrm{O}$ aprendiz memoriza o novo conteúdo sem fazer relação com conteúdos existentes, como ocorre, por exemplo, em um processo de alfabetização em que há a aprendizagem de pares de sílabas sem sentido [4] ou, então, na aprendizagem de matemática ou física quando há a pura memorização de conceitos e fórmulas.

Neste tipo de aprendizagem, "geralmente os conteúdos se relacionam quase que exclusivamente com o contexto em que foi aprendido. Para recordar o conteúdo, o aprendiz tem que recordar a situação em que foi memorizado" [21] e se limita a ele. Com isso, pode-se concluir que o contexto de um problema pode dar sentido ao conteúdo, mas não garante que promova um aprendizado significativo, que fará sentido para o aluno.

$\mathrm{Na}$ aprendizagem significativa, o novo conteúdo se relaciona, ancora-se em outros conceitos relevantes pré-existentes na estrutura cognitiva do aprendiz, definidos como subsunçores. O armazenamento de informações no cérebro é organizado e forma uma hierarquia conceitual, na qual elementos mais específicos são ligados (assimilados) a conceitos mais gerais, inclusivos [4]. Por exemplo, em algoritmos, se o conceito de estrutura (bloco de comandos) já existe na estrutura cognitiva do aluno, ele servirá de subsunçor para novas informações referentes a certos tipos de estruturas, como, por exemplo, a estrutura condicional (bloco de comandos restringidos por uma condição e é executado apenas uma vez) e estruturas de repetição (bloco de comandos restringido por uma condição que pode ser executado várias vezes).

Nesse processo, o aprendiz deve aprender o conceito e não a forma, ordem ou situação que este (conceito) foi apresentado [21]. Assim, não basta que os problemas sejam apresentados em um contexto, é necessário ser significativo para o aluno, ou seja, que os elementos se relacionem com elementos preexistentes na estrutura cognitiva do aluno.

As duas formas de aprendizagem podem ocorrer por descoberta ou por recepção. A aprendizagem por descoberta acontece quando o que deve ser aprendido é descoberto pelo aprendiz, e é ele (aprendiz) quem constrói e testa hipóteses. Já na aprendizagem por recepção, o que deve ser aprendido é apresentado ao aprendiz em sua forma final, ocorre, geralmente, em aulas expositivas [4, 21].

Ausubel não trata as duas formas de aprendizagem como sendo dicotômicas, mas sim como um "continuum" [4], pois há casos em que o processo inicia-se por uma aprendizagem mecânica e no decorrer deste se transforma em significativa. Isso ocorre, por exemplo, quando o aluno se depara com um conhecimento de uma área completamente nova, neste caso, inicia com uma aprendizagem mecânica até que sejam criadas estruturas cognitivas iniciais, subsunçores para este novo conhecimento. A aprendizagem começa a ser significativa quando os subsunçores vão ficando mais elaborados e capazes de ancorar novas informações.

\subsubsection{Condições para Aprendizagem Signi- ficativa}

Segundo Moreira e Masini [4], a criança pequena adquire conhecimento através de um processo conhecido como formação de conceitos, que é a aquisição espontânea de ideias genéricas por meio de experiências empíricoconcretas. Este é um tipo de aprendizagem por descoberta que consiste essencialmente em abstrair aspectos comuns característicos de uma classe de objetos ou eventos que varia contextualmente.

Os autores complementam que, em idade escolar, a criança já tem desenvolvido um conjunto de conceitos que permitem a aprendizagem significativa, o qual é adquirido 
através de um processo de assimilação, diferenciação progressiva e reconciliação integrativa dos conceitos [22].

$\mathrm{Na}$ aprendizagem significativa, os novos conhecimentos, potencialmente significativos, relacionam-se de forma não-arbitrária e substantiva a algum conhecimento prévio, especificamente relevante, existente na estrutura cognitiva do aprendiz [20, 23]

Não-arbitrário quer dizer não-aleatório, entende-se como a existência de uma relação lógica e explícita entre o novo conhecimento e algum outro já existente na estrutura cognitiva do aprendiz. Por exemplo, entender o conceito de cadeira só se tornará significativo para o aprendiz se ele tiver em sua estrutura cognitiva, de forma clara, o conceito de sentar e, assim, fazer a relação entre estes dois conceitos.

Por substantiva, compreende-se que, uma vez aprendido determinado conceito, esse pode ser expresso em linguagem sinônima e transmitir o mesmo significado, ou seja, o aprendiz conseguirá explicar com suas próprias palavras o conceito aprendido, como, por exemplo, expressar o significado de cadeira com suas palavras independente do tipo de cadeira.

Para Moreira e Masini [4], para uma aprendizagem significativa é necessário que:

O material a ser aprendido seja potencialmente significativo para o aprendiz, ou seja, relacionável a sua estrutura de conhecimento de forma não-arbitrária e nãoliteral (substantiva);

O aprendiz manifeste uma disposição de relacionar o novo material de maneira substantiva e não-arbitrária a sua estrutura cognitiva.

Como citado, o material tem que ser potencialmente significativo para o aprendiz e, para isso, é necessário que ele tenha disponível em sua estrutura cognitiva subsunçores os quais o novo material possa ser ancorado. $\mathrm{Na}$ inexistência desses, Ausubel recomenda o uso de organizadores prévios para servirem de âncora para a nova aprendizagem e leve ao desenvolvimento de conceitos subsunçores [4].

Organizadores prévios são elementos, conceitos que situam os aprendizes ao que será aprendido e servem como ponte entre o que o aprendiz já sabe e o que deve saber. São como resumos ou sumários do conhecimento novo, construídos a partir de conceitos mais gerais, mais fáceis de assimilar e mais próximos da realidade do aprendiz. Um organizador prévio que poderia ser utilizado para o ensino de variáveis e constante em algoritmos, por exemplo, são as incógnitas e as constantes de equações matemáticas, conteúdos aprendidos no Ensino Fundamental e Médio. A revisão desses conteúdos pode servir de ponte para o entendimento do novo conceito.
Além dos organizadores prévios e subsunçores, outro fator fundamental para que a aprendizagem significativa ocorra é a motivação. De acordo com Moreira e Masini [4], não importa o quão significativo seja o material a ser aprendido e as condições cognitivas do aprendiz, pois se ele não estiver motivado em aprender, dificilmente terá uma aprendizagem significativa.

\subsection{Trabalhos Relacionados}

Considerou-se como similares os trabalhos que tratavam sobre a influência dos jogos ou a sua utilização para apoio a aprendizagem de programação introdutória, bem como ferramentas interativas de apoio ao desenvolvimento de programas. Das publicações encontradas deu-se preferência as que apresentavam alguma descrição sobre os desafios utilizados, resultado pautado em um experimento ou relato de experiência, desta forma foram analisados: Game2Learn [24]; Wu's Castle [25]; Scratch [26,27,28]; Escracho [12].

O jogo é um elemento que está sendo inserido na educação e que em grande parte apresenta bons resultados, principalmente no que diz respeito à motivação dos alunos. Dentre as contribuições desses trabalhos, estão os desafios de programação utilizados, a forma como foram contextualizados, a utilização dos enredos e a amarração que deve ter entre os desafios e o enredo, características que nem sempre são observadas em jogos educacionais. Também, houve contribuição em relação aos experimentos feitos, a forma como foi escolhida a amostra aplicada a intervenção, os instrumentos e métodos de coleta e análise dos dados.

\section{Procedimentos Metodológicos}

Essa pesquisa baseou-se no método hipotético-dedutivo, pois partiu de um problema e seguiu para a obtenção de sua solução por meio de verificação de hipóteses [17]. Sob o ponto de vista da natureza, a pesquisa é aplicada, por utilizar conceitos e tecnologias existentes para verificar as hipóteses.

Realizaram-se três análises, na primeira fez-se um teste de hipótese verificando o desempenho dos alunos, relativo à nota obtida nas avaliações. $\mathrm{Na}$ segunda avaliaram-se os erros cometidos na resolução das questões, norteadas pelas ações pré-definidas e, na terceira, analisou-se os comentários dos alunos no questionário final.

Abordou-se o problema central de forma quantitativa e qualitativa. Mensurou-se o quantitativamente o desempenho dos alunos nas avaliações realizadas e verificaram-se as hipóteses. Após analisou-se qualitativamente as ações realizadas pelos alunos, na resolução do problema proposto, sua opinião sobre a avaliação e sobre a relevância da estrutura e do contexto das questões. 
Os enunciados são utilizados como variáveis de entrada para validação da Etapa 6, no procedimento de análise relacionado aos testes de hipóteses.

A seguir nesta seção são detalhadas as duas grandes etapas realizadas na pesquisa. (i) A elaboração e validação das diferentes modalidades do instrumento de mensuração utilizado; e (ii) O delineamento e realização do quase experimento com o público alvo e correspondente análise dos resultados.

\subsection{Elaboração dos Enunciados}

Conforme a Teoria da Relevância, para que o enunciado seja relevante, deve-se observar duas condições: o interesse e motivação do ouvinte e as habilidades e pretensões do falante. A primeira condição pode estar relacionada com o perfil do aluno e seu interesse e conhecimento do contexto do enunciado, que o torna mais ou menos atrativo e compreensivo; e a segunda com a estrutura, quais informações e forma como são apresentadas.

Para a teoria da Aprendizagem Significativa, a condição de aprendizagem está relacionada ao material, que deve ser potencialmente significativo, e a motivação do aluno em querer aprender. O contexto e a estrutura se relacionam a essas duas premissas, pois um contexto conhecido e com uma estrutura adequada, facilitam a compreensão do enunciado, visto que, o aluno se utiliza de estruturas cognitivas preexistentes, fazendo relações com conhecimentos já adquiridos (subsunçores), o que minimiza o esforço cognitivo (otimizando a relevância), e pode motivar o aluno a querer resolver, também considerando sua afinidade com o contexto.

Visto a importância do enunciado, principalmente do contexto e estrutura, deu-se atenção a sua elaboração, a qual teve por base quatro etapas: (1) análise dos enunciados de livros; (2) estudo do perfil dos alunos; (3) construção do enunciado; (4) avaliação e validação dos enunciados. A seguir, a descrição de cada etapa.

\section{Etapa1 - Análise dos Enunciados de Livros}

Buscando verificar como são apresentados os enunciados dos exercícios de problemas algorítmicos, pelos livros base citados nos plano de ensino dos cursos de bacharelado em Ciência da Computação no Brasil, realizou-se uma pesquisa, em 2011, em que houve participação de 51 universidades $^{1}$, distribuídas em todas as regiões do país.

Foram analisados os livros que tinham como propósito

\footnotetext{
${ }^{1}$ Para definir esta amostra, foi realizada uma pesquisa dos cursos superiores de Bacharelado em Ciência da Computação, ativos na modalidade presencial, cadastrados no Mec. Esta informação foi obtida através do sistema e-Mec (http://emec.mec.gov.br/), o qual permite consultar de forma on-line as instituições e cursos cadastrados e reconhecidos. A pesquisa foi realizada em novembro de 2011 e retornou 353 ocorrências.
}

o desenvolvimento de algoritmos; contemplavam o conteúdo relacionado as etapas iniciais da aprendizagem de programação ou seja: estruturas de controle: seleção e repetição; e disponibilizavam lista de exercícios.

Para cada questão, observou-se a forma de enunciação do problema, indícios do processo de resolução, presença de exemplificação e contexto. O problema diz respeito ao que deve ser feito, isso implica na motivação do aluno em querer resolvê-lo problema, dar sentido ao esforço a ser empregado na sua resolução. Verificou se este era objetivo ou contextualizado. Considerou-se objetivo quando o enunciado apresentava apenas o que era para ser feito, de forma bem direta e o contextualizado quando o enunciado descrevia o que era para ser feito e, também, contemplava a sua importância ou aplicação em algum contexto como escolar, empresarial, matemático e outros.

O processo de resolução de problemas está relacionado à forma como se resolve o problema, não necessariamente de forma algorítmica. O processo de resolução pode contribuir na relação entre os subsunçores e, conforme, como organizadores prévios, contribuindo, também, para a otimização da relevância. Foram considerados três níveis: explícito, implícito e inexistente. O processo é explícito quando apresenta explicitamente a forma como se processa o problema. Por exemplo, quando o enunciado pede para que seja feito um algoritmo que calcule o N! e é demostrado matematicamente o processo de cálculo de um fatorial. É implícito quando o enunciado se apresenta de tal forma que dá indícios dos passos a serem realizados ou, então, são apresentadas as fórmulas que demostram o processo, mas, sem nenhuma descrição desse. E, por último, inexistente quando o enunciado apenas informa o que é para ser feito, sem nenhuma descrição sobre o processo.

A exemplificação, também, foi analisada, pois além de auxiliar na compreensão do problema, ainda, pode ser utilizada como casos de teste dos algoritmos. Elemento fundamental para verificar se o que o ouvinte entendeu é o que o falante pretendia. Auxilia na busca da relevância ótima e na produção de um material mais significativo. Nesse item, considerou-se a presença ou ausência de exemplos.

Por fim, analisou-se o contexto dos problemas apresentados. O contexto pode influenciar na motivação do aluno em querer resolver o problema, contem elementos subsunçores, bem como, na otimização da relevância do enunciado. Buscou-se saber se era puramente matemático, ligado a sistemas de informação, tais como sistemas de recursos humanos, comercial e outros. O tipo de contexto

Destas, foram selecionadas aleatoriamente 180 universidades, e realizado contato, via e-mail, com as coordenações dos cursos solicitando as bibliografias utilizadas nas disciplinas introdutórias de programação e algoritmos. Foram obtidas respostas de 51 universidades. 
que foi considerado estava relacionado ao foco e à aplicação do problema.

\section{Dados Obtidos da Etapa 1}

Foi utilizado como base de dados os 12 livros didáticos analisados no trabalho de Zanini e Raabe [14]. A partir das informações abstraídas desse trabalho foram aplicados os critérios de seleção e acesso. O Quadro 1 apresenta o número de questões relacionadas aos conteúdos.

\begin{tabular}{|l|c|}
\hline \multicolumn{1}{|c|}{ Conteúdo } & \multicolumn{1}{|c|}{$\begin{array}{c}\text { Número de } \\
\text { questões }\end{array}$} \\
\hline Estrutura de condição & 91 \\
\hline Estruturas de repetição & 110 \\
\hline $\begin{array}{l}\text { Geral: Estrutura de condição e } \\
\text { repetição }\end{array}$ & 227 \\
\hline \multicolumn{2}{|c|}{ Total } \\
\hline
\end{tabular}

Quadro 1 - Número de questões analisadas por conteúdo Maiores detalhes podem ser obtidos em [15].

\section{Descobertas da Etapa 1}

Ao analisar a forma como o problema era apresentado, observou-se que dos 428 enunciados, $64.72 \%$ descreveram-no de forma objetiva e $35.28 \%$ de forma contextualizada, segundo evidencia a Figura 1.

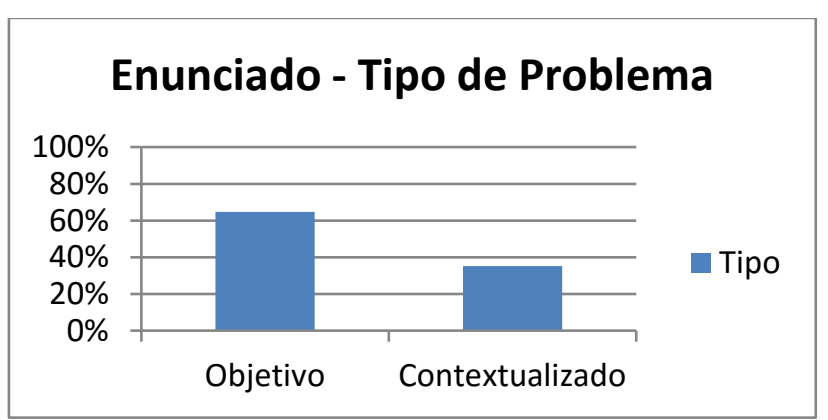

Figura 1 - Forma como o problema foi descrito no enunciado

Em relação ao processo de resolução, $18.46 \%$ dos enunciados apresentaram o processo de forma explícita, $21.03 \%$ de forma implícita e $60.51 \%$ não apresentaram indício do processo, como mostra a Figura 2.

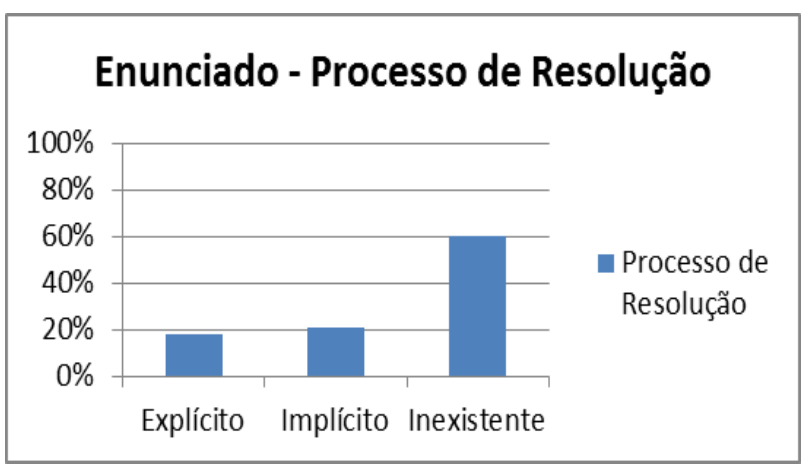

Figura 2 - Forma como o processo de resolução foi apresentado no enunciado.

Apenas 10,51\% dos enunciados continham exemplos de resolução, ficando $89.49 \%$ sem exemplos, conforme descrito na Figura 3.

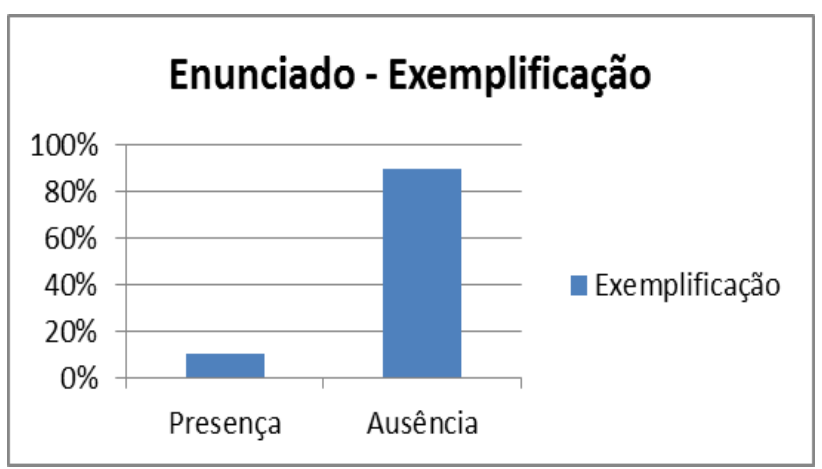

Figura 3 - Forma como o processo de resolução foi apresentado no enunciado.

Quanto aos contextos, analisou-se e tabulou-se de acordo com a Figura 4. Nesse é apresentado os seis primeiros, com maior percentual de ocorrência, veja listagem completa, com as descrições de cada um, em Papastegiou [15].

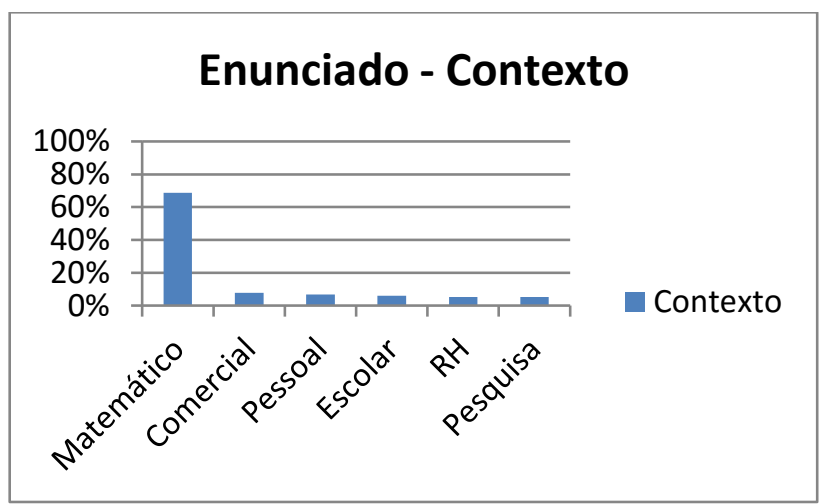

Figura 4 - Contexto observado nos enunciados

Como pode-se observar, a predominância é do contexto matemático $(68,68 \%)$. Em segundo lugar, o comercial $(7,86 \%)$, em seguida tem-se o pessoal $(6,86 \%)$, escolar $(6,12 \%), \mathrm{RH}(5,24 \%)$ e pesquisa $(5,24 \%)$.

\section{Discussão da Etapa 1}

Constatou-se que geralmente os enunciados apresentam o problema de forma objetiva, informando apenas o que é para ser feito, de forma direta, sem uma aplicação em um contexto maior. Isso reflete na motivação do aluno e no grau de relevância em querer resolver o problema, pois a resolução é algo sem sentido, pouco significativo, e que exige um esforço de processamento maior.

Considerou-se o processo de resolução inexistente, não trazendo informações de como resolver o problema além 
de omitir informações, o que exige um esforço cognitivo maior e um esquema mental mais desenvolvido, com presença de mais subsunçores, para poder compreender e interpretar o enunciado.

A grande maioria dos enunciados não apresenta exemplificação, limitando-se aos dados contidos no problema. Um exemplo é importante, pois, auxilia na compreensão do processo de resolução, na construção de subsunçores, amenizando o esforço cognitivo.

Quanto ao contexto, verificou-se que o matemático é predominante. Esse contexto é comum aos alunos, entretanto, por ser puramente matemático sem uma aplicação que faça sentido prático ao educando o torna desmotivador, exige a presença de subsunçores e aumenta o processamento cognitivo, o que diminui a relevância.

\section{Etapa 2 - Estudo do Perfil dos Alunos}

Com o objetivo de construir enunciados mais significativos, que contenham elementos conhecidos, possibilitando a otimização da relevância e promoção de motivação, tem-se, como uma das ações, que definir os contextos a serem utilizados.

Com base nas pesquisas realizadas, observou-se que o contexto mais utilizado nos enunciados de algoritmos, seguindo os livros didáticos, é o matemático. Um outro contexto que está sendo foco de muitos estudos e que teoricamente parece ser promissor, principalmente por promover motivação é o de jogos, indícios encontrados em diversas pesquisas $[6,8,9,11,12]$.

Pautado nesses dois contexto, fez-se uma pesquisa de perfil para verificar a afinidade dos alunos com esses. Buscou-se responder as seguintes questões:

- qual nível de afinidade os alunos de Programação Introdutória tem com Matemática (baixo, médio, alto)?

- qual nível de afinidade os alunos de Programação Introdutória tem com Jogos (baixo, médio, alto)?

- qual o estilo de jogo que os alunos de Programação Introdutória têm mais interesse?

\section{Dados Obtidos da Etapa 2}

A pesquisa foi realizada com oito turmas de programação introdutória de seis instituições de ensino superior de quatro estados brasileiros, Ceará, Santa Catarina, São Paulo e Rio Grande do Sul. Dessas, 246 alunos concordaram em participar e consentiram que seus dados fossem publicados.

Os livros didáticos utilizados são os indicados no trabalho de Zanini e Raabe [14], conforme apresentados abaixo.

\begin{tabular}{|c|}
\hline Livros Analisados \\
\hline $\begin{array}{l}\text { FORBELLONE, A. L. V.; EBERSPACHER, H. F.. Lógica de Programação: A } \\
\text { construção de algoritmos e estrutura de dados }(1993,2000,2005,2010) \text {. }\end{array}$ \\
\hline $\begin{array}{l}\text { MANZANO, J.A.N.G. OLIVERIA, J. F. Algoritmos : lógica para } \\
\text { desenvolvimento de programação de computadores. (1996, 1997, 1999, 2000, } \\
\text { 2001, 2002, 2004, 2005, 2006, 2007, 2008, 2010) }\end{array}$ \\
\hline $\begin{array}{l}\text { FARRER, H. at al. Programação estruturada de computadores: Algoritmos } \\
\text { estruturados. (1989, 1998, 1999, 2009) }\end{array}$ \\
\hline SALVETTI, D. D. BARBOSA, L.M. Algoritmos. $(1988,1998,2004)$ \\
\hline $\begin{array}{l}\text { ASCENCIO, A. F. G; CAMPOS, E. A. V. Fundamentos da program } \\
\text { computadores: Algoritmos, Pascal, C/C++ e Java. }(2002,2003,2007,20\end{array}$ \\
\hline \multirow{2}{*}{$\begin{array}{l}\text { MIZRAHI, V. V. Treinamento em Linguagem C }(1990,1993,2006,2007,2008) \\
\text { SALIBA, W. L. C. Técnicas de Programação: Uma Abordagem Estruturada. } \\
(1992,1999)\end{array}$} \\
\hline \\
\hline $\begin{array}{l}\text { TREMBLAY, J. P. Ciência dos computadores: Uma Abordagem Algorítmica. } \\
\text { (1983) }\end{array}$ \\
\hline $\begin{array}{l}\text { MANZANO, J. A. N. G.; OLIVEIRA, J. F. Estudo dirigido de algoritmos. (1997, } \\
2002,2008,2010)\end{array}$ \\
\hline DEITEL, H. M. DEITEL, P. J. C++: como programar. $(2005,2006,2010)$ \\
\hline FARRER, Harry et al. Pascal Estruturado. $(1985,1999,2009)$ \\
\hline PUGA, S. RISSETTI, G. Lógica de programação e estrutur \\
\hline
\end{tabular}

Figura 5 - Livros Analisados por Zanini e Raabe [14]

\section{Descobertas da Etapa 2}

Para analisar o nível de afinidade com Matemática e com Jogos, criou-se três níveis: "Baixa - Não gosto", "Média - gosto mais ou menos" e "Alta - Gosto". O aluno teria de selecionar um dos três níveis. Os dados obtidos estão representados na Figura 6.

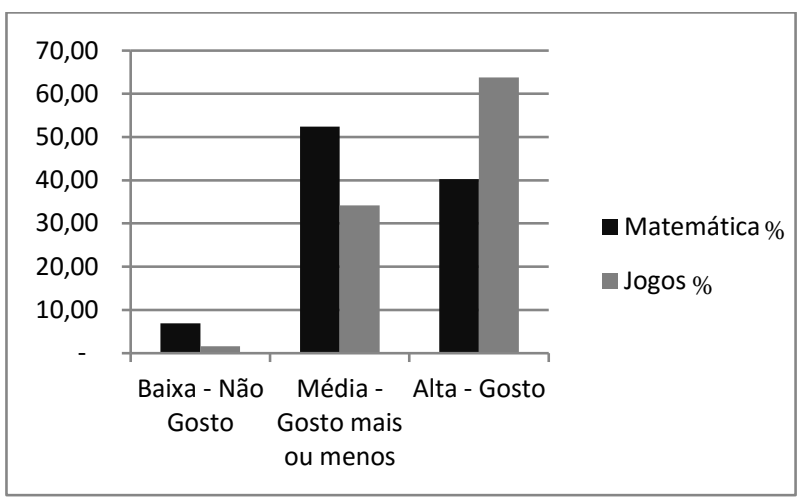

Figura 6 - Nível de afinidade dos alunos de Programação Introdutória com Matemática e Jogos.

Verificou-se que os alunos, de um modo geral, possui maior interesse em atividades realizadas com jogos.

Para analisar o estilo de jogos, apresentou-se uma lista com 12 gêneros (tiro, luta, corrida, quebra-cabeça, plataforma, esporte, aventura, RPG, simulação, estratégia, MMOGs, cassino) e o aluno poderia assinalar todos os quais se identificava. Caso considerasse algum outro gênero, que não estivesse na lista, poderia incluí-lo na opção “outro". A Figura 7 evidência os dados obtidos. 


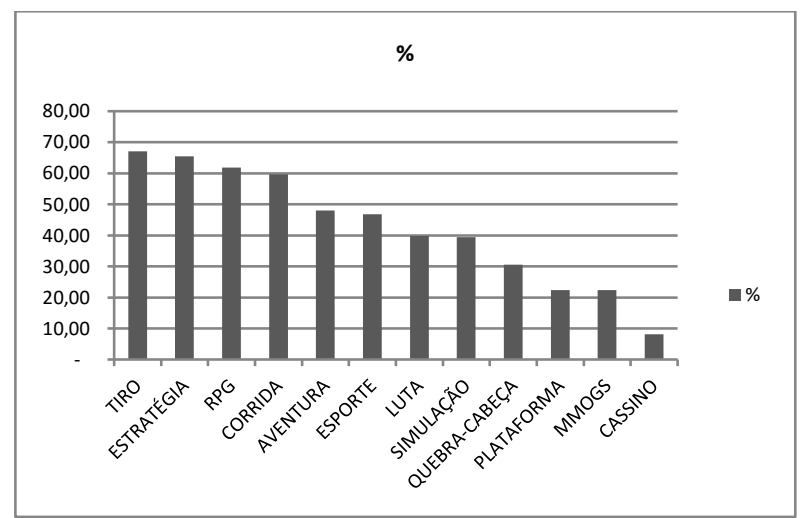

Figura 7 - Gênero de jogos preferidos pelos alunos de Programação Introdutória.

Dentre os gêneros apresentados, a grande parte dos alunos possuem afinidade com jogos de tiro, estratégia e RPG.

\section{Discussão da Etapa 2}

Essa etapa foi fundamental para definir o contexto a ser utilizado no experimento, visto que uma aplicação em um contexto conhecido contribui para a ligação do que está sendo solicitado com os elementos pré-existentes na estrutura cognitiva do alunos, otimizando a relevância do enunciado e promovendo maior motivação.

Pode-se observar que tanto o contexto matemático quanto o contexto de jogos são comuns a grande parte dos alunos, plausíveis de serem utilizados na elaboração dos enunciados. Dentre o contexto de jogos, tornou-se necessário definir o gênero, e os mais citados e que serão considerados na próxima etapa foram tiro, estratégia e RPG.

\section{Etapa 3 - Construção do Enunciado}

Para construir os enunciados, além do contexto, foi necessário definir os conteúdos a serem abordados. Considerando os conteúdos da disciplina, foram utilizadas as estruturas básicas de programação: constantes, variáveis, expressões, comandos de entrada e saída, estrutura de condição e estruturas de repetição (loop).

Para definir os conteúdos lógico-matemáticos, optouse por criar questões em que fossem realizados processos de contagem (incremento ou decremento de valores) e calculo de percentual. Esses conteúdos foram escolhidos por serem comuns em atividades encontradas nos livros didáticos de Algoritmos nesta fase inicial.

Os critérios usados na construção dos enunciados foram:

- Contexto: matemático e jogos (tiro e RPG)

- Estrutura: estruturado e não estruturado - Considerouse estruturado quando contextualizado em um assunto específico, mostra indícios do processo de resolução de forma explícita e apresenta exemplos, deixando claro o que deve ser feito. Na ausência de alguma característica, classificou-se como não estruturado, deixando liberdade à criação.

- Conteúdo foco: constantes, variáveis, expressões, comandos de entrada e saída, estrutura de condição e estrutura de repetição.

- Processos lógico-matemáticos: contagem e percentual.

Criou-se quatro avaliações cada uma contendo duas questões distribuídas conforme contexto e enunciado. Assim, tem-se:

Avaliação 1 - Jogos com enunciado estruturado (JE)

Avaliação 2 - Jogos com enunciado não estruturado (JN)

Avaliação 3 - Matemático com enunciado estruturado (ME)

Avaliação 4 - Matemático com enunciado não estruturado (MN)

Reforça-se que as questões eram iguais com relação aos requisitos técnicos de solução, teriam de apresentar os mesmos processos lógicos. O que as diferenciavam eram o contexto e a estrutura (quantidade de informação apresentada). Os exemplos destas questões podem ser encontrados no link http://goo.gl/nGS32h.

\section{Etapa 4 - Avaliação e Validação dos Enunciados}

Após elaborar os enunciados, esses, foram avaliados e validados sobre o ponto de vista do contexto, estrutura, relevância conceitual e técnica de cada questão e a equivalência entre as questões-grupos.

\section{Validação do contexto do jogo e lógica de resolução}

Inicialmente, elaboraram-se dois enunciados, um no contexto de jogos de tiro em primeira pessoa (FPS) e outro no contexto de jogos de RPG.

Com o objetivo de verificar se os enunciados eram coerentes com o contexto dos jogos em questão (tiro e RPG) e se era possível compreender qual a solução esperada, solicitou-se a um grupo de alunos, que cursam a disciplina de "Computação Gráfica e Modelagem de Jogos" da $4^{\text {a }}$ fase de um curso de Graduação em Ciência da Computação, resolverem e avaliar estes enunciados. Essa escolha foi proposital, visto que os alunos já eram considerados "experientes" no conteúdo de algoritmos abordados na questão e tinham uma relação prática e conhecimento teórico em jogos.

Nessa validação confirmou-se os gêneros dos jogos, pois, os alunos, ao lerem o enunciado, identificaram o primeiro como sendo de "FPS - tiro em primeira pessoa" e o segundo como sendo "RPG". Entretanto, observou-se que alguns elementos utilizados não eram fiéis, coerentes com o que é utilizado em jogos dessa natureza, como, por exemplo, no FPS a quantidade de munição do armamento, que eram mais focadas na matemática simples e não eram compatíveis com a realidade dos jogos. Perceberam, 
ainda, questões de coerência e lógica, pois no enunciado de RPG o cálculo indicado para calcular o dano não era coerente com esse tipo de jogo porque quanto mais fraco estava o monstro ou os guerreiros, menor era o dano, o que deveria ser o inverso. Outro problema evidenciado diz respeito ao processo lógico para finalizar o jogo, visto que o cálculo utilizado o tornaria interminável. A partir dessas observações, ajustou-se os enunciados.

\section{Validação da estrutura e equivalência das questões}

As avaliações foram encaminhadas para três professores, com o intuito de avaliar se as questões poderiam ser consideradas equivalentes tecnicamente, ou seja, se usariam os mesmos processos lógicos na resolução, tendo como produto final o mesmo algoritmo.

\section{Validação com o público-alvo}

Após validar os avaliações, realizou-se uma aplicação piloto com o público-alvo, alunos da disciplina de Algoritmos I da primeira fase de um curso de graduação em Ciência da Computação. O objetivo dessa validação era verificar o tempo necessário para aplicação e necessidade de algum ajuste nas questões.

Em relação ao tempo, pode-se observar que seriam necessárias em média de 2 horas para aplicação.

Quanto às questões, foi detectado que os textos estavam muito longos, precisavam ser mais objetivos. Houve reclamação com o número de controle e processos envolvidos nas questões, gerando um código muito grande.

Pautadas nessas observações ajustou-se as questões.

\subsection{Experimento}

O experimento foi composto por sete fases: (1) Definição da amostra; (2) aplicação de um questionário de perfil, (3) divisão dos grupos; (4) aplicação das avaliações (intervenção) e de um questionário final; (5) correção da avaliação; (6) procedimento de análise; (7) resultados.

\section{Fase 1: Definição da Amostra}

A população alvo dessa pesquisa são alunos de cursos superiores na área de Computação e Informática, que tenham como objetivo o desenvolvimento de sistemas, e estejam cursando a disciplina de programação introdutória.

Foram feitos convites para participação no experimento por meio de e-mails encaminhados aos coordenadores dos cursos de informática reconhecidos pelo MEC de 453 IES (instituição de ensino superior), e-mail para a lista ALG-PROG-L, lista de discussão da SBC (Sociedade Brasileira de Computação) com foco no ensino de programação, e verbalmente para os participantes do WEI - 2012 (Workshop de Ensino Computação), ao apresentar um artigo sobre enunciados disponíveis em livros didáticos de algoritmos, tema relacionado a essa pesquisa.

Muitos se mostraram interessados, entretanto, alguns fatores limitaram a participação, os principais foram a greve das Instituições de Ensino Federais e o não oferecimento da disciplina no $2^{\circ}$ semestre de 2012 em algumas instituições.

A amostra final foi composta por 246 estudantes de oito turmas de seis IES distribuídas em diferentes estados de regiões distintas do Brasil conforme ilustra o Quadro 1.

\begin{tabular}{|c|l|l|}
\hline Turma & \multicolumn{1}{|c|}{ Instituição } & \multicolumn{1}{|c|}{ Estado } \\
\hline 1 & Universidade 1 & Santa Catarina \\
\hline 2 & Universidade 2 & Santa Catarina \\
\hline 3 & Universidade 3 & Santa Catarina \\
\hline 4 & Universidade 4 & São Paulo \\
\hline 5 & Faculdade 1 & Rio Grande do Sul \\
\hline 6 & Faculdade 2 & Ceará \\
\hline 7 & Faculdade 2 & Ceará \\
\hline 8 & Faculdade 2 & Ceará \\
\hline \multicolumn{3}{|c|}{ Quadro1 - Descrição das instituições participantes }
\end{tabular}

\section{Fase 2: Questionário inicial}

Com o intuito de convidar os alunos a participarem da pesquisa, consentindo a utilização de seus dados, e, também, de conhecer seus perfis de interesse relacionados a jogos e a matemática, solicitou-se, via professor da disciplina, o preenchimento de um questionário, o qual foi disponibilizado de forma eletrônica. O questionário ficou disponível para preenchimento do início do semestre até a aula em que se abordou o conteúdo de estruturas de repetição. Obteve-se 246 respondentes.

\section{Fase 3: Divisão dos grupos}

Os elementos do enunciado em estudo são contexto e estrutura, sendo respectivamente, jogos ou matemático e estruturado ou não estruturado. Assim, os enunciados constituem-se de quatro maneiras, como seguem:

1. contexto de jogos e estruturado (JE);

2. contexto de jogos e não estruturado $(\mathrm{JN})$;

3. contexto matemático e estruturado $(\mathrm{ME})$;

4. contexto matemático e não estruturado $(\mathrm{MN})$.

Para analisar o desempenho dos alunos, perante essas formas de enunciados, dividiu-se a amostra em quatro grupos, sendo que, cada um realizou um tipo de avaliação. A divisão seguiu dois passos:

1 - Estratificação: divisão da amostra em estratos baseados na afinidade com matemática (alta, média e baixa - obtida no questionário inicial), afinidade com jogos (alta, média, baixa - obtida no questionário inicial) e desempenho base (uma nota de 0 a 10, disponibilizada pelo professor da turma representando o desempenho médio dos alunos antes de abordar o conteúdo de estruturas de repetição - classificado como: "Bom" nota $>=8$, "Mediano" $5>=$ nota $<$ 
8 ou "Com dificuldade" nota $<5$ ).

2 - Atribuição: criação de quatro grupos, selecionados, através de seleção aleatória simples, dentro de cada estrato.

Esta divisão teve como objetivo equalizar os perfis dos estudantes nos quatro grupos de forma a obter uma confiabilidade semelhante a seleção amostragem aleatória [29].

\section{Fase 4: Aplicação das avaliações (intervenção) e Ques- tionário Final}

As avaliações e questionário final foram aplicados no final do semestre letivo, após concluir o conteúdo sobre estruturas de repetição. Os professores, das turmas, receberam as avaliações nominais, juntamente com o questionário final, e entregaram aos alunos responderem.

Acordou-se em fazer na sala de aula, individualmente, sem consulta e com a presença do professor. Após, encaminharam à pesquisadora para correção e análise. Alguns professores o fizeram via correio e outros por e-mail (escaneados).

\section{Fase 5: Correção das avaliações}

As avaliações possuem duas questões que são equivalentes entre os quarto grupos (JE, JN, ME, MN). Para correção subdividiu-se cada questão em ações, necessárias para resolvê-la, descritas no Quadro 2.

\begin{tabular}{|c|c|}
\hline Questão1 & Questão2 \\
\hline $\begin{array}{l}1 \text { - atribuir dados pré-determi- } \\
\text { nados a duas variáveis (ação1, } \\
\text { ação2); }\end{array}$ & $\begin{array}{l}1 \text { - atribuir dados pré-deter- } \\
\text { minados a uma variável } \\
\text { (ação1); }\end{array}$ \\
\hline $\begin{array}{l}2 \text { - ler (digitar) três informa- } \\
\text { ções (ação3, ação4, ação5); }\end{array}$ & $\begin{array}{l}2 \text { - ler (digitar) três informa- } \\
\text { ções (ação2, ação3, ação4); }\end{array}$ \\
\hline $\begin{array}{l}3 \text { - fazer uma verificação, para } \\
\text { definir o tipo de cálculo, se } \\
\text { adição ou subtração (ação6); }\end{array}$ & $\begin{array}{l}3 \text { - fazer duas verificações, } \\
\text { uma para definir o tipo de } \\
\text { cálculo, se adição ou subtra- } \\
\text { ção, e a outra para definir } \\
\text { uma de duas variáveis que } \\
\text { irá sofrer o cálculo (ação5, } \\
\text { ação6); }\end{array}$ \\
\hline $\begin{array}{l}4 \text { - efetuar um cálculo, con- } \\
\text { forme verificação, envolvendo } \\
\text { adição e subtração (ação 7); }\end{array}$ & $\begin{array}{l}4 \text { - efetuar um cálculo, con- } \\
\text { forme verificação, envol- } \\
\text { vendo adição ou subtração e } \\
\text { percentual (ação 7); }\end{array}$ \\
\hline $\begin{array}{l}5 \text { - mostrar os dados das variá- } \\
\text { veis (ação8); }\end{array}$ & $\begin{array}{l}5 \text { - repetir os passos, a partir } \\
\text { do item } 2 \text {, N vezes (ação9). }\end{array}$ \\
\hline $\begin{array}{l}6 \text { - repetir os passos, a partir } \\
\text { do item } 2, \mathrm{~N} \text { vezes (ação9). }\end{array}$ & \\
\hline
\end{tabular}

Quadro2 - Descrição das principais ações a serem realizadas em cada questão.

Para cada ação foi atribuído um peso de 0 a 3 representando o seu nível de acerto, conforme mostrado no Quadro3.

\begin{tabular}{|c|l|}
\hline Peso Questão & \multicolumn{1}{c|}{ Descrição } \\
\hline 0 & Ausente - não foi apresentado. \\
\hline 1 & $\begin{array}{l}\text { Incorreto - o que foi feito não está correto, entre- } \\
\text { tanto, o aluno apresentou algum indício de com- } \\
\text { preensão do que teria de ser feito. }\end{array}$ \\
\hline
\end{tabular}

\begin{tabular}{|c|l|}
\hline 2 & $\begin{array}{l}\text { Incompleto - a lógica de forma geral está correta, } \\
\text { mas, há erro de sintaxe, falta de alguma informa- } \\
\text { ção ou ajuste. }\end{array}$ \\
\hline 3 & Correto. \\
\hline
\end{tabular}

Quadro3 - Descrição dos níveis de acerto para as ações

Ao final somaram-se os pesos e converteram-na em uma nota equivalente entre 0 e 10 . Para a conversão foi usada à regra de proporção (soma dos pesos / peso máximo * 10). Esse valor representa o desempenho do aluno na questão. Para o desempenho do aluno na avaliação, foi feita a média aritmética ( (desempenho questão1 + desempenho questão2)/2).

\section{Fase 6: Procedimento de Análise}

Inicialmente analisou-se o desempenho dos alunos, através de testes de hipóteses, sendo elas:

$\mathrm{H} 1$ - enunciados contextualizados em jogos promovem melhor desempenho do que os contextualizados em matemática;

$\mathrm{H} 2$ - enunciados mais estruturados promovem melhor desempenho do que os menos estruturados.

As hipóteses foram pormenorizadas, considerando-se o desempenho base dos alunos, a afinidade com jogos, afinidade com matemática, a estrutura e o contexto.

Para verificar se as diferenças encontradas são válidas estatisticamente (grau de confiança de $5 \%=p=0,05$ ), aplicou-se a técnica de regressão logística, a qual permite estimar a probabilidade $p$ associada com uma resposta dicotômica para vários valores de uma ou mais variáveis explicativas.

As variáveis independentes consideradas foram as notas dos alunos antes da intervenção (desempenho base), afinidade com matemática, afinidade com jogos, estrutura e contexto. A variável dependente é o desempenho médio dos alunos na realização do experimento.

Entraram no modelo as variáveis explicativas dicotomizadas desempenho base X1 (0 quando o desempenho estava abaixo da mediana e 1 quando o desempenho era superior a mediana), afinidade com matemática X2 ( 0 quando sua afinidade era média ou baixa e 1 quando sua afinidade era alta), afinidade com jogo X3 (0 quando é média ou baixa e 1 quando é alta), estrutura X4 (0 quando a questão, referente ao jogo ou a matemática, era não estruturada e 1 quando a questão, referente ao jogo ou a matemática, era estruturada) e contexto X5 (0 quando a questão envolve matemática e 1 quando a questão envolve jogo).

A fim de usar as variáveis X1, X2, X3, X4 e X5 para prever a probabilidade de que essas expliquem a variabilidade do desempenho médio do aluno após experimento, $\mathrm{p}$, ajusta-se o modelo, conforme equação 1 : 
$\ln \left(\frac{\hat{p}}{1-\hat{p}}\right)=\hat{\alpha}+\hat{\beta}_{1} X_{1}+\hat{\beta}_{2} X_{2}+\hat{\beta}_{3} X_{3}+\hat{\beta}_{4} X_{4}+\hat{\beta}_{5} X_{5}$

Assumindo que a relação entre $\ln [\mathrm{p} /(1-\mathrm{p})]$ (variável dependente) e as variáveis independentes seja linear, o modelo de regressão logística maximiza a função de verossimilhança com o algoritmo de Newton-Raphson.

Após, verificada as hipóteses, fez-se outras análises pautadas nas ações realizadas pelos alunos na solução dos problemas e nas respostas apresentadas no questionário final.

\section{Fase 7 - Resultados}

Foram aplicadas quatro tipos de avalições:

JE - Contexto de Jogos e Estruturada;

JN - Contexto de Jogos e Não estruturada;

ME - Contexto Matemático e Estruturada

MN - Contexto Matemático e Não estruturada;

O desempenho obtido nas avaliações está apresentado no Figura 8.

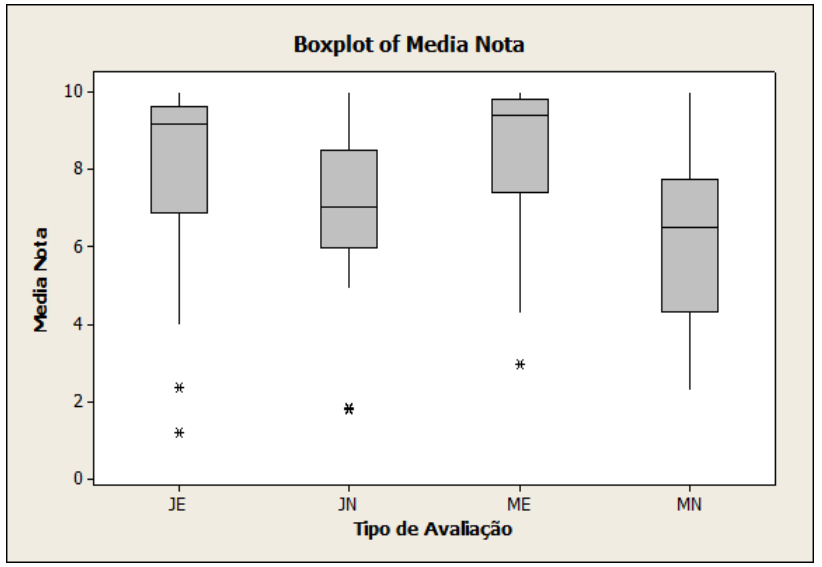

Figura 8 - Desempenho por avaliação

Pode-se observar que o melhor desempenho foi obtido nas avaliações estruturadas, com menor variabilidade acima da mediana.

A Figura 9 apresenta o percentual de acertos, considerando, também, o contexto e a estrutura.

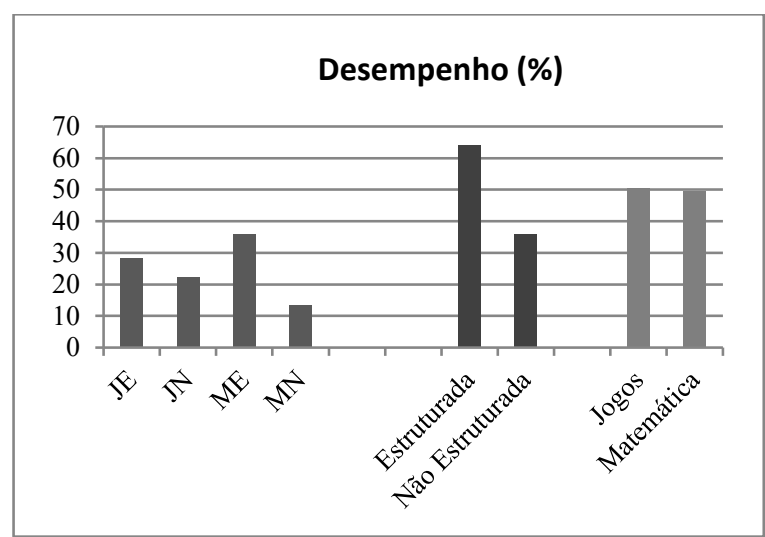

Figura 9 - Desempenho \% considerando estrutura e contexto

O Gráfico 4 mostra que o melhor desempenho foi obtido na avaliação de Matemática Estruturada, seguindo do Jogo Estruturado, logo Jogo não estruturado e por fim Matemática não estruturada. Observou-se que a estrutura faz diferença na resolução, entretanto, o contexto não.

Os resultados vão de acordo com as teorias estudadas, pois, conforme visto no perfil dos alunos, o contexto matemático e de jogos era comum a grande parte deles, o que pode ter contribuído para a ligação entre o que estava sendo expresso com o sua estrutura cognitiva, entretanto, a falta de elementos estruturais podem ter dificultado essa ligação.

Para fundamentar melhor essa observação, fez-se uma análise estatística através da técnica de Regressão Logística. Nessa análise considerou-se duas hipóteses:

H1 - Enunciados estruturados em jogos promovem melhor desempenho do que os contextualizados em matemática.

$\mathrm{H} 2$ - Enunciados estruturados promovem melhor desempenho do que os não estruturados.

$\mathrm{O}$ que motivou a análise de $\mathrm{H} 1$ foram os indícios de que o contexto puramente matemático é abstrato, que não há uma aplicação prática da vivência do aluno e que muitos possuem deficiências conceituais, adquiridas ao longo dos anos. Desta forma, requer-se de maior esforço de processamento, de estruturas cognitivas mais elaboradas, o que diminui a relevância e a motivação do aluno em querer resolver a questão. Por outro lado, o contexto de jogos algo que faz parte da vivência, da cultura, dos alunos, que provê motivação, entusiasmo, maximizando a relevância, minimizando o esforço cognitivo, visto que há subsunçores pré-existentes.

Através da análise da regressão logística não se obteve significância estatística que comprovasse a hipótese H1. $\mathrm{Na}$ análise das respostas nos questionários finais, em uma visão qualitativa, observou-se que no contexto matemático o vilão foi a falta de uma aplicação prática, o qual o tornou desmotivante. No contexto de jogos os alunos que curtiam FPS e RPG se entusiasmaram com a atividade, já os que não possuíam tanta afinidade com esses gêneros ou com jogos não tiveram tanta aceitação, reclamaram da extensão do texto, comentaram que estava confuso, havia muitas informações e deveria ser mais objetivo. Na análise das questões observou-se que as notas foram afetadas, em grande parte, devido as omissões, não realização de uma ação esperada, em alunos que não possuíam afinidade com jogos ou com os gêneros em específico.

$\mathrm{Na}$ hipótese $\mathrm{H} 2$ analisou-se a influencia da estrutura no desempenho dos alunos. Ao analisar o perfil desses alunos, detectou-se que são os que possuíam um bom desempenho 
base (nota na disciplina anterior ao experimento disponibilizada pelo professor da disciplina), ou seja, alunos que já possuíam uma estrutura cognitiva desenvolvida, não necessitando de elementos auxiliares para a criação de novos subsunçores.

A análise feita pela Regressão Logística corroborou com a hipótese de que enunciados mais estruturados promovem melhor desempenho do que os não estruturados, principalmente, quando o contexto é matemático. Nas avaliações não estruturadas, os alunos, citaram a falta, ou omissão, de informações como um grande dificultador, deixando o enunciado complexo, confuso. Isso pode ser confirmado na análise das soluções, pois, o pior desempenho foi constatado na questão 1 do contexto matemático não estruturado em que a falta de informações fez com que a solução apresentada fosse diferente da esperada. Essa questão possui estrutura e contexto típico dos livros didáticos utilizados como referência básica da disciplina. Em contrapartida, nas avaliações estruturadas o exemplo foi apontado como ponto forte, sanando dúvidas deixadas pelo enunciado e servindo de base para validar a solução. Alguns alunos comentaram que a avaliação estava muito extensa, pouco objetiva, com informações desnecessárias. Ao analisar o perfil desses alunos, detectou-se que são os que possuíam um bom desempenho base (nota na disciplina anterior ao experimento disponibilizada pelo professor da disciplina), ou seja, alunos que já possuíam uma estrutura cognitiva desenvolvida, não necessitando de elementos auxiliares para a criação de novos subsunçores, como apresentado na teoria da seção 2 .

Certamente os resultados obtidos não são definitivos e passiveis de discussão. A seguir são discutidas a validade interna e externa do experimento realizado.

\section{Ameaças a Validade Interna}

Conforme Trochim [29], a validade interna é a inferência feita sobre relações de causa-efeito, ou seja, se o elemento experimentado foi o que realmente causou o efeito observado, não sendo causado por outros fatores externos a experimentação. Qualquer explicação alternativa para o efeito observado é considerado uma ameaça à validade interna, pois coloca em dúvida a relação de causa-efeito.

\section{Ameaças de História}

Esse tipo de ameaça se caracteriza pelo acontecimento durante o período de experimentação que possa modificar o efeito observado, como por exemplo, vivencia do aluno, material utilizado pelos professores, aulas complementares entre outros.

Considerando que se tinham oito turmas de seis instituições, em que os professores, a metodologia de ensino e o material utilizado eram diferentes, foi necessária uma ação que amenizasse essa ameaça. Inicialmente os alunos de todas as turmas foram considerados como um único grupo, a partir desse criou-se estratos, conforme perfil, e, após, os quatro grupos experimentais. Mas nem todos os estratos continham alunos de todas as turmas, o que pode ter causado um viés no resultado. Outro fator pode ser a afinidade com determinado gênero de jogos, pois se considerou a afinidade com jogos e não a afinidade com determinado gênero.

\section{Ameaças de Maturação}

Essa ameaça está relacionada com o fato de que os alunos amadurecem com o tempo, independente dos experimentos realizados. Essa ameaça é amenizada devido aos critérios utilizados para a divisão dos grupos, entretanto um dos critérios utilizados que pode ter afetado o processo de seleção é o desempenho base, pois foi medido pelo professor da disciplina e não foram usados critérios rigorosos para o tempo na disciplina em que foi feita a medida, proporcionado maior ou menor tempo de maturação, construção de mais ou menos subsunçores.

\section{Ameaças de Instrumentação}

Caracteriza-se por diferenças encontradas entre os instrumentos utilizados para a medição. Essa é uma ameaça amenizada pela validação técnica feita com três professores da disciplina, em que analisou-se a equivalência entre os instrumentos, entretanto, com o baixo desempenho apresentado na questão 1 da avaliação no contexto matemático não estruturada requer novas observações.

\section{Ameaça de Mortalidade Seletiva}

Ocorre quando uma das amostras possui maior propensão para abandonar o experimento. Nessa pesquisa houve abandono entre as primeiras ações e o experimento, mas não chegou a afetar a quantidade mínima de participantes em cada grupo.

\section{Ameaça de Seleção}

Essa ameaça está relacionada à semelhança entre os dois grupos. Se os grupos não forem semelhantes, não será possível afirmar que o resultado foi causado pelo tratamento proposto e não pela diferença entre os grupos. A seleção é muito importante, pois as ameaças histórica e maturação podem ser potencializadas se não houver equivalência entre os grupos.

Nesse experimento, foram utilizados quatro grupos, e a divisão foi baseada em estratos constituídos pela afinidade com matemática, afinidade com jogos e desempenho base.

\section{Ameaças De Validade Externa}


A ameaça externa refere-se as possibilidades de generalizações dos resultados. A partir dessa pesquisa não se pode generalizar os resultados de forma ampla, apesar de ser experienciada por diversas turmas, com diversos professores e metodologias, pois, está limitada a uma única aplicação e a algumas regiões do país.

\section{CONCLUSÕES}

Com isso conclui-se que apesar de jogos serem considerados elemento cultural, fazerem parte do cotidiano dos alunos, não podem ser generalizados, pois, existem diversos gêneros, cada um com um conjunto de características específicas, podendo ser considerados como contextos diferentes. Então o mais importante é ter um contexto conhecido, independente se for em jogos, matemática ou outro. Isso vai ao encontro com a Teoria da Relevância e a Teoria da Aprendizagem Significativa, em que a falta de conhecimento, afinidade com gênero, ocasiona um processamento cognitivo extra devido a falta de subsunçores para que as informações contidas na situação problema possa ancorar-se.

O que realmente faz a diferença é a estrutura do enunciado, que para alunos iniciantes é importante que o enunciado seja contextualizado em um contexto conhecido, que as informações sejam apresentadas de forma explicita, com indícios do processo de resolução e com exemplificação. Na medida em que amadurecerem, criarem subsunçores, deve-se abstrair as informações até conseguir construir as estruturas complexas.

\section{Referências}

[1] L.S. Barbosa; T.C.B. Fernandes; A.M.C. Campos, Takkou: Uma Ferramenta proposta ao Ensino de Algoritmos. Workshop de Educação em Computação (WEI), Congresso Anual da Sociedade Brasileira de Computação, Natal-RN, 2011.

[2] J. N. Mendes, Software Educativo para apoio à aprendizagem de programação. In: Taller Internacional de Software Educativo, 2001, Santiago. Disponível em: < http://www.c5.cl/ieinvestiga/actas/tise01/pags/charlas/charla_mendes.htm> acessado em: 10/12/2010

[3] R. P. Santos; H. A. X. Costa, Análise de Metodologias e Ambientes de Ensino para Algoritmos, Estruturas de Dados e Programação aos iniciantes em Computação e Informática. INFOCOMP Journal Of Computer Science, Lavras/MG - Brasil, v. 5, n. 1, p. 41-50, 2006.
[4] M. A. Moreia; E. F. S. Masini, Aprendizagem significativa: A Teoria de David Ausubel. São Paulo: Moraes. 1982.

[5] J. Mattar, Games em educação: como os nativos digitais aprendem. São Paulo: Pearson Education, 2010.

[6] K. Becker; J. R. Parker. All I ever needed to know about programming, I learned from re-writing classis arcade games. In: ACM SIGCSE Bulletin, USA, v. 37, n. 2, p. 103-106, jun. 2005.

[7] A.L.V. Forbellone; H.F. Eberspächer, Lógica de programação: a construção de algoritmos e estruturas de dados. São Paulo: Makron Books, 1993.

[8] M. Prensky, Digital game-based learning. Computers in Entretainment (CIE), USA, v. 1, n. 1, p 21-25, out. 2003.

[9] D. C. Cliburnm The effectiveness of games as assignments in na introductory programming course. In. ANNUAL ASEE/IEEE FRONTIERS IN EDUCATION CONFERENCE, 36. 2006, San Diego, California, USA. Proceeding... USA:IEEE, 2006. P. 6 -10.

[10] J. D. Bayliss Using games in introductory course: tips from the trenches. In. ACM Technical Symposium On Computer Science Education, 40, 2009, Chattanooga, USA. Proceedings... New York: ACM, 2009. P. 337 - 341.

[11] M. Feldgen; O. Clúa, Games as a motivation for freshman students learn programming. In: ASEE/IEEE FRONTIERS IN EDUCATION, 34, Savannah, GA. Proceedings... 2004. P. S1H1S1H16.

[12] E. A. Jesus; A. L. A. Raabe. Avaliação Empírica da Utilização de um Jogo para Auxiliar a Aprendizagem de Programação. In: XXI Simpósio Brasileiro de Informática na Educação, 2010, João Pessoa. Anais, 2010.

[13] A. L. A. Raabe; J. M. C. Silva, da. Um ambiente para atendimento às dificuldades de aprendizagem de algoritmos. In: XIII Workshop sobre Educação em Computação, 2005, São Leopoldo, RS, 2005.

[14] A.S. Zanini; A. L. A. Raabe. Análise dos enunciados utilizados nos problemas de programação introdutória em cursos de Ciência da Computação no Brasil. In: Workshop sobre Educação em Computação. 2012.

[15] M. Papastergiou, Digital Game-Based Learning in high school Computer Science education: Impact on educational effectiveness and student motivation. Computers \& Education, v. 52, n. 1, p. $1-12,2009$. 
[16] A. Mitchell; C. Savil-Smith, The use of computer and video games for learning: a review of the literature. London: Learning and Skills Development Agency, 2004.

[17] S. S. Borges, et al. Gamificação Aplicada à Educação: Um Mapeamento Sistemático. In: XXIV Simpósio Brasileiro de Informática na Educação. 2013.

[18] D. Wilson, Relevance theory. In L. Horn \& G. Ward (eds) The Handbook of Pragmatics. Blackwell: Oxford, 2004.

[19] D. Sperber; D. Wilson, Relevance, chap 1, sections 1, 2, 4-7. 1995.

[20] D. P. Ausubel, Aquisição e retenção de conhecimentos: uma perspectiva cognitiva. Lisboa: Plátano Edições Técnicas, 2003.

[21] M. G. S. e Silva, Psicologia da Educação I: Livro didático. Palhoça: UnisulVirtual, 2007.

[22] J. D. Novak, A Theory of education. Nova York: Cornell University Press, 1977.

[23] D. P. Ausubel,; J, D. Novak; H. Hanesian, Psicologia Educacional. Rio de Janeiro: Interamericana Ltda. 1980.

[24] T. Barnes et al., Game2Learn: building CS1 learning games for retention. In: ANNUAL SIGCSE Technical Symposium on Computer Science Education, 12. 2007, Dundee, Scotland. Proceedings.. New york: ACM, 2007

[25] M. Eagle; T. Barnes, Experimental Evalution of an Education Game for Improved Learning in Introductory Computing, In.: SIGCSE Technical Symposium on Computer Science Education. 40. Chattanooga. USA. Proceedings... USA: ACM,2009.

[26] D.J. Malan; H.H. Leitner, (2007). Scratch for budding computer scientists. In Proceedings of the 38th SIGCSE Technical Symposium on Computer Science Education. ACM, 223-227.

[27] I. F. Kereki, Scratch: Applications in Computer Science 1. Proceedings - Frontiers in Education Conference, FIE, p. T3B7-T3B11, 2008.

[28] H.M. Cristovão, Aprendizagem de Algoritmos num contexto significativo e motivador: um relato de experiência. In: XVI Workshop de Educação em Computação, Congresso Anual da Sociedade Brasileira de Computação, Para, 2008.

[29] W. M. K. Trochim, Research Methods. Disponível em: http://www.socialresearchmethods.net/kb/. Acesso em 15/01/2012. 